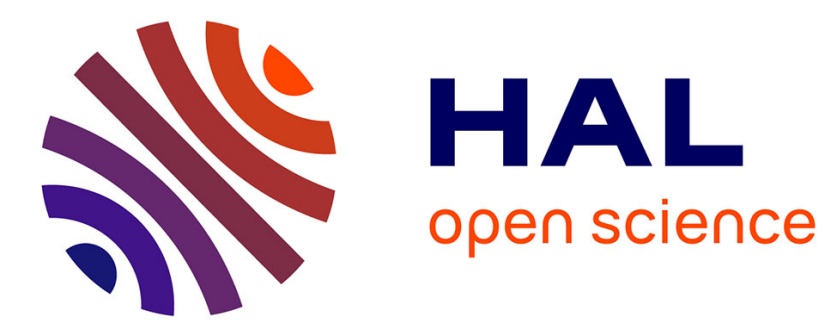

\title{
The complexity of co-opetitive networks
}

\author{
Jean Sébastien Lacam, David Salvetat, Jean-Sébastien Lacam
}

\section{To cite this version:}

Jean Sébastien Lacam, David Salvetat, Jean-Sébastien Lacam. The complexity of co-opetitive networks. Business Process Management Journal, 2017, 23 (1), pp.176-195. 10.1108/BPMJ-12-20150187 . hal-02083201

\section{HAL Id: hal-02083201 https://hal.science/hal-02083201}

Submitted on 9 Nov 2021

HAL is a multi-disciplinary open access archive for the deposit and dissemination of scientific research documents, whether they are published or not. The documents may come from teaching and research institutions in France or abroad, or from public or private research centers.
L'archive ouverte pluridisciplinaire HAL, est destinée au dépôt et à la diffusion de documents scientifiques de niveau recherche, publiés ou non, émanant des établissements d'enseignement et de recherche français ou étrangers, des laboratoires publics ou privés. 


\title{
THE COMPLEXITY OF CO-OPETITIVE NETWORKS
}

\author{
Jean-Sébastien LACAM \\ Adjunct professor \\ ESSCA Business School \\ 1 rue Lakanal - BP 40348 \\ 49003 Angers cedex 01 - France \\ Phone: 06.72.08.85.24 \\ jslacam@yahoo.fr \\ David SALVETAT \\ Professor \\ La Rochelle Business School - CEREGE \\ 102, rue des Coureilles \\ 17000 La Rochelle, France \\ Phone: 06.58.23.11.62 \\ salvetatd@esc-larochelle.fr
}

\begin{abstract}
Purpose: Many firms engage in co-opetitive projects during which they have simultaneously competitive and collaborative relationships with many rivals in a complex network. A co-opetitive network offers them access to a large volume of resources and knowledge, for example, to support new markets and/or territories. So, does the network grow with the scope of the co-opetition project?

Design/Methodology: An empirical study of 106 French boating intermediate-sized enterprises (ETIs) and small and medium enterprises (SMEs) provides a descriptive and explanatory analysis of co-opetitive networks.

Findings: Our results support this definition of a complex co-opetitive network only when the objectives of a firm are part of the geographical expansion of its activities. In contrast, these relations remain simple (dyadic) when a firm favours a strategy of diversifying its activities while maintaining its unique local geographical market.
\end{abstract}


Research limitations/implications: Firstly, the work is based on a quantitative methodology, so is static. It would be interesting to analyse the process of the building of coopetitive relationships and opportunism between rival firms, for example through a qualitative study. Secondly, this work focuses on boating companies in France. It may be appropriate to consider the sanctions placed on the opportunism of foreign firms in co-opetition. Thirdly, future work could increase understanding, not only of the nature of reprisals inflicted on individualistic co-opetitors, but also on the structure, objectives and results of these reprisals.

Value: Our study deepens our knowledge of the definition, composition and determinants of co-opetitive networks.

\section{KEYWORDS}

Multi-market and multi-point co-opetition, network, dyadic or complex relationship, ETIs, SMEs.

\section{INTRODUCTION}

Research in strategic management has long opposed the competitive perspective with regard to the relational approach to the production of economic rents. The awareness that firms are increasingly simultaneously engaged in rivalry and co-operation has paved the way for other research on the combination and interrelation between these relational modes (Bengtsson and Kock, 2000). The literature in the field has gradually come to recognize that the success of a firm, through achieving and maintaining its competitive advantage, requires the development of strategies both competitive and co-operative (Lado et al., 1997). Coopetition allows rivals to pool resources and knowledge in order to share the risks of a new 
project, realize economies of scale, enter new sectors and geographic markets, support innovation and learning, and so on (M'Chirgui, 2005).

Co-operation is a strategy that concerns interactions situated at the interpersonal (Enberg, 2012), intra-organizational (Tsai, 2002) or inter-organizational (Luo et al., 2006) level. Wilhelm et al. (2011) argue that a network in co-opetition is now recognized as a classic relational mode between competitors. SMEs and large firms choose to build a coopetitive network of resources and expertise to meet the needs initiated by their sectoral and geographical policies (Luo, 2007; Kock et al., 2010).

However, the nature of co-opetitive relationships is still being debated in the scientific community (Bengtsson and Kock, 2014).

While collective strategies take place within a co-opetitive strategy with dyadic (or simple) relationships (Gnyawali and Madhavan, 2001), network theory considers co-opetition as a number of relationships (complex relations) between multiple competitors (Bengtsson et al., 2010). Therefore, the literature indicates that co-opetition is used either in simple networks or within complex networks but do not show how forms of co-opetition interrelate with specific types of network. The link between the practice of a co-opetitive strategy and the adoption of a network based on its complexity has not been established.

Thus, our research question is: Does the complexity of collaborative relationships between rivals characterize co-opetitive strategies? To answer this question, a quantitative study of French nautical sector firms was conducted and 106 ETIs and SMEs participated. Our quantitative study on ETIs and SMEs involved in a co-opetitive strategy is designed to complement the majority of the conceptual and qualitative works conducted with large firms (Gast et al., 2014). 
Our results indicate that co-opetitive relationships are complex when co-opetitors internationalize in other geographical areas but are simple when co-opetitors diversify their markets.

\section{THEORETICAL BACKGROUND}

\section{The network as a competitive tool}

Gulati et al. (2000: 203) define networks as "a firm's set of relationships, both horizontal and vertical, with other organizations - be they suppliers, customers, competitors, or other entities - including relationships across industries and countries. These strategic networks are composed of interorganizational ties that are enduring, are of strategic significance for the firms entering them, and include strategic alliances, joint ventures, longterm buyer-supplier partnerships, and a host of similar ties". According to Gnyawali and Madhavan (2001), the network is used by a firm as a strategic instrument to benefit from an exchange of information, resources and status (enabling legitimacy, power and recognition) in order to gain better competitive advantages. For the individual company, the advantage of integration with a network is the ability to pursue and enhance its distinctive sector, which, to the best of our knowledge, is an unexplored field of research, the unpredictability of competition and rapid technological change (Miles and Snow, 1986).

A network can emerge unplanned from a process following the recognition of the interdependence between firms, or from a deliberate strategy by one of the firms wanting to ally for strategic purposes (Jarillo, 1988). Two economic motivations originate the development of an inter-firm network: cost sharing and the joint exploitation of complementary assets (Dyer and Singh, 1998). The interest in pursuing the latter collaborative form gradually exceeds the simple benefit of cost sharing for some firms. To better focus on their core business, some firms mobilize distinctive external resources and competencies, i.e. 
competencies not integrated with their core business, to complete their value chain (Assens, 2003). As part of a defensive aim, a network can help firms to block rivalry and create dominant norms to defend their competitive position (Swaminathan and Moorman, 2009). As part of a policy of expansion, a network can bring to a firm the resources, knowledge and cost controls necessary to the extension of its activities and geographical markets (Jarillo, 1988; M'Chirgui, 2005).

Two main network architectures have emerged and are frequently cited according to the level of centralization. The first type of inter-organizational network is known as a "community network" and represents horizontal co-operation in the medium and long term built are mutual and reciprocal distinct in this context (Assens, 2003). Of equivalent weight, these competitors are looking for relational returns through the sharing and pooling of investments, knowledge, resources and unique capabilities; all of which is framed by necessarily effective governance mechanisms to ensure their synergistic combination or a reduction in transaction costs (Dyer and Singh, 1998). Thus, Gomes-Casseres (2003) refers to the emergence of "constellations of firms". A constellation aims to collect and manage the resources of its members. Through their links, firms are groups united in achieving a common goal. The competitive advantage is based on the group in relation to other firms or other constellations. Corporate networks can then compete against each other (Dyer and Singh, 1998) and inter-network competition develops. Consequently, the commitment of a firm to a network can come, not through choice, but as a constraint to global competition.

The second type of inter-organizational network is the "network company" model. According to Powell et al. (1996), this type of vertical network is a response to the need for a focal firm to establish a more flexible organizational structure that is less cumbersome and focused on the development of its technology and strategic process. Thus, the competitive advantage of a firm can come from its position in a network and its organizational 
relationships, which are necessary for the efficiency and effectiveness of its business. According to the social network approach, Gnyawali and Madhavan (2001) show that a firm's ability to access and use a network's resources varies depending on its position within it. The actor is all the more central if it has a set of controls, power and the ability to manipulate interactions between other network members.

A network, therefore, allows a firm to adapt to a structure and changes in the market, to have a better positioning within it, to operate with other players synergistically in the use of resources and then to implement an approach designed to reduce coordination costs (Gulati et al., 2000). Beyond the market and position, the network has become a strategic tool managed by a firm to achieve its competitive advantage over its opponents outside the network (Jarillo, 1988).

\section{The network: a collaborative structure}

A network can be operated as a tool of growth by helping its members achieve activity levels that would be inaccessible individually (Levin and McDonald, 2006). Alongside a purely economic approach, Gulati (1998) shows that economic activities are influenced by the social context in which firms are integrated. Thus, because of their common strategic interdependence, competitors can relate and become closer due to their interactions in the markets for products and resources (Gulati, 1998).

The interaction of firms, therefore, influences their competitive strategies. A relational network is defined as a set of specific social connections between organizations and between individuals, such as friendship or group membership. Thus, the effectiveness of a network of relationships can be understood through the trust and relationships that develop between individuals. Personal relationships create opportunities for co-operation by deepening the trust and commitment of the parties to the relationship (Larson, 1992). Alongside the individual 
perspective, the benefits granted to a firm by its network of relationships can also be understood structurally.

First, being rooted in a common social network is the most common explanation for the formation of co-operative relationships between firms (Gulati and Gargiulo 1999). Lazega (1992) describes the structural equivalence between actors of a network that are not necessarily directly connected to each other but have the same relations with one or more players in the system. Thus, the presence of members with common [structural] attributes integrated into their respective networks (suppliers, customers, and so on) can promote and support their efforts to create links. Firms that share similar relationships can be recognized more easily. Thus, the proximity of one firm to another can help them recognize that their association is more viable than their opposition.

Second, network complexity is characterized as a network that brings together more than two firms that maintain strong and sustainable exchange relationships that are sources of gains (Thorelli, 1986). Network complexity is defined as the number of previous collaborations between members of the same environment (Gulati and Gargiulo, 1999) and can help a firm to identify potential participants more easily and develop more co-operative opportunities (Prashant and Singh, 2009). Complexity promotes the development of cooperative opportunities (Prashant and Singh, 2009), facilitating the emergence of common standards and establishing penalties that ensure social control and a reduction in opportunism during the collaboration (Burt, 2012). Bengtsson and Kock (2000) develop the concept of coopetition as the simultaneity of competitive and co-operative behaviour between rivals in a simple (dyadic) relation. Dagnino and Padula (2007) enrich the concept by presenting a coopetitive relationship as complex (with multiple co-opetitors). Co-opetition is presented as an evolving relationship in either a simple or a complex network, depending on the focus of the academic work. When competitors cooperate, a chain of actions is initiated which propagate 
through the network. At one level, several firms can engage voluntarily in a co-opetitive relationship. Dagnino and Padula (2007) suggest a complex co-opetition network (e.g. rivalry and competition on various activities in their value chains). At a second level, Salvetat and Géraudel (2011) evoke co-opetition induced by a third actor that imposes simultaneous cooperation and rivalry between firms for the success of a particular project. Wilhelm and Kohlbacher (2011) point out that the stress of co-opetition fosters technology transfer and knowledge creation between a principal and the many providers in its network. During a project, for example, the collaborative activities coordinated by the principal (such as seminars and workshops) improve the capacity of its providers, while at the same time maintaining rivalry through the comparison of performance. Thus, competition may be organized simultaneously in co-operation. A firm may also compel other organizations to enter into co-opetition (Tsai, 2002).

Therefore, Bengtsson and Kock (2000) argue that a relationship between two firms is affected by and affects other relationships in a network structure because the connections are interconnected, with opponents involved in confrontation and/or collaboration with members of their respective networks. Thus, several competitors can have multiple relationships, which are different and evolve with the context (Bengtsson and Kock, 2014). Co-opetition evolves in complex networks (Dagnino and Padula, 2007).

Dense networks allow firms to familiarize themselves with their current allies and those allies emerging through common third parties. Connectivity and complexity between partners describe the density of connections within a network (Gulati et al., 2000). Density is measured by the number of partners involved in the exchange process, the likelihood of developing future relations between partners and the likelihood that these relationships are subject to open discussion between these partners: "Complex tasks require that many parties interact to complete a product or service, which enhances the likelihood that mutual contacts 
will evolve, rather than strictly bilateral, exclusive exchanges" (Jones et al., 1997, 923). This occurs as a result of two mechanisms: the reduction of information asymmetries and the increase of trust between firms (Gulati et al., 2000). Good-quality information is easily distributed in a high-density network because each firm is properly connected to all of its members (Uzzi, 1997). A dense network also facilitates the emergence of common standards, shared behaviours and the application of effective sanctions (Burt, 2012). Standards and shared values are criteria for selecting members of the network and thus reducing the risks posed by opportunism (Nooteboom et al., 1997). Economic exchange is then governed by the norms of reciprocity and trust which self-regulate interdependent stakeholders and provide social control (Larson, 1992).

Finally, firms are connected through strong links that can be based on a shared trust to develop and protect their common project (Gulati, 1995). Strong links reflect intense and reciprocal relationships that require time and energy to create and maintain. Their presence promotes the emergence of firms with a common experience of accumulated information, language and specific know-how (Dyer and Singh, 1998). During the formation of cooperation, strong ties can allow a reduction in costs or be a source of social and economic support that moderates the risk associated with the co-operation. During such co-operation, these links can act as a governance mechanism to guide a collaborative project (Gulati, 1995).

Thus, firms develop regular exchanges in the long term which constitute their relational networks (Larson, 1992). These connections are an important source of sustainable competitive advantage for a firm (Gulati et al., 2000).

The network: a co-opetitive strategy for ETIs and SMEs?

Padula and Dagnino (2007) develop the notion of co-opetition within a complex network, which involves several firms deciding to co-operate on various levels of 
their respective value chains, while simultaneously competing with others. Co-opetition combines co-operation with rivals to create a greater business potential and competition with rivals within that larger share (of the market) (Bouncken et al., 2015). For example, Wang et al. (2013) point out that the planning or execution of marketing policies for the promotion of a tourism destination in the Central Florida region is often not managed by a single firm, but by collective structures that bring together several local competitors. The realization of a common marketing campaign is motivated by the collective management of costs associated with such an operation, through the exchange of complementary knowledge between partners and the opportunity to diversify their portfolio of offerings to improve their own competitive advantage.

Thus, Luo (2007) suggests a co-opetition network conducted by the sectoral and territorial policies of firms. Co-opetition can enhance the activity of existing firms or support their diversification through access to resources and external expertise (Bengtsson et al., 2010). Competitive pressures and similarities among rival bids for the same domestic market also promote the simultaneity of firm's competitive and collaborative behaviour (Luo, 2007). Furthermore, a strategy of territorial expansion requires mobilization by a firm of a number of resources and competences that it would find difficult to achieve alone (Hamel et al., 1989).

Therefore, co-opetition is one a solution for a firm wishing to facilitate expansion in various remote areas of its historical operating territory through, for example, cost reduction and the development of a transnational network of information, knowledge, resources and varied competences (Kock et al., 2010; Gast et al., 2014).

Generally limited in their resources, SMEs are often competitive in their co-opetitive strategy (Morris et al., 2007). These are based on co-opetition in order to create, produce and distribute their offers in sectors and very competitive or unrecognized territories (Morris et al., 2007; Ritala, 2012). Needs related to their sector and geographic policies are employed to 
guide the construction of their co-opetitive network resources and skills (Luo, 2007; Kock et al., 2010). Collaboration helps SMEs to gather the necessary resources to renew their existing business or create a diversified portfolio of activities in a local or global environment (Dagnino and Padula, 2007; Gnyawali and Park, 2009; Kock et al., 2010). To do this, a firm mobilizes a co-opetitive network composed of social relations from their connections with other firms and a network of knowledge and inventions derived from previous experiments (Wang et al., 2014). Learning is stimulated by co-opetition (Tsai, 2002). Thus, international development pushes SMEs to engage in co-opetition (Kock et al., 2010). Their international networks accelerate their competitive positions abroad through, for example, their access to new local knowledge, which reduces the risks and costs of their implementation. Moreover, co-opetition supports different types of innovation (Ritala, 2012). First, co-opetition can enable incremental innovations that include minor improvements to products and/or existing services through a specialization policy. On the other hand, co-opetition can enable radical innovations that develop new products and services through a policy of diversification. SMEs use co-opetition to strengthen and increase their sectoral and geographic environments through the sharing of knowledge. Globalization and constant technological development thus lead SMEs to engage in co-opetition (Coy, 2006). Through their networks, firms seek to improve their performance by sharing the resources and risks associated with their projects (Bouncken et al., 2015). Despite the existence of some threats from network relationships, such as the loss of strategic resources or competitive advantage with respect to a stronger partner, co-opetition appears to be crucial to the survival of SMEs (Tomaszewski, 2013; Gast et al., 2014.).

In view of the above, we agree with the conclusions of Bengtsson and Kock (2014), who claim that we need to deepen our knowledge of co-opetition in order to define its true nature. First, we found that the specific characteristics of SMEs regularly led them to 
collaborate with their competitors in order to renew the terms of their competitive advantage. Their co-opetitive networks support their industry and national policies. Yet the majority of works on co-opetition to date focus on large firms (Dagnino and Padula, 2007). It is, therefore, necessary to increase our knowledge of how SMEs deploy this strategy. Second, the network seems to play an important role in the creation and structuring of forms of coopetition developed by SMEs (co-opetition specialization, diversification, local or international). However, there is still no consensus among authors regarding the definition of co-opetitive relationships (Bengtsson and Kock, 2014). Co-opetition is understood either as a simple co-operative (dyadic) relationship between only two direct competitors (Bengtsson and Kock, 2000; Gnyawali and Madhavan, 2001) or as a complex network of value creation that brings together many competitors, customers and suppliers (Dagnino and Padula, 2007; Wilhelm and Kohlbacher, 2011). It seems necessary to evaluate the degree of complexity of a co-opetitive network according to the sectoral and territorial scope of SMEs.

Therefore, three hypotheses are formed (see Figure 1.):

Figure 1. Theoretical model

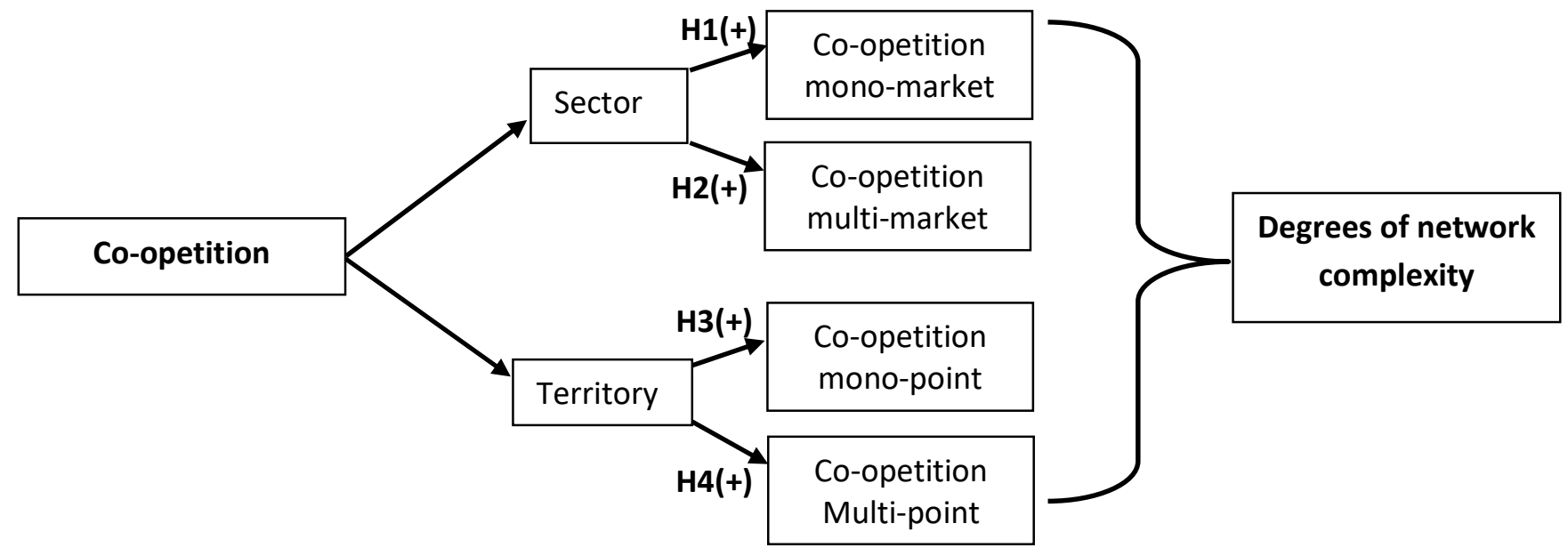


H1: The more a firm has a strategy of co-opetition, the more the firm specializes its activities in a single market.

$\mathrm{H} 2$ : The more a firm has a strategy of co-opetition, the more the firm diversifies its activities in many markets.

H3: The more a firm has a strategy of co-opetition, the more the firm focuses its activities on a single country.

H4: The more a firm has a strategy of co-opetition, the more the firm develops its activities in many countries.

\section{METHOD}

\section{Boating and sampling}

The majority of works have studied the co-opetitive process within a single firm or a small group of firms selected according to certain structural criteria (such as size and age). This qualitative approach suggested the use of the process-based approach to co-opetition we adopted in our study A few studies have been interested in examining co-opetitive practices using quantitative methods in order to describe and explain them. We adopted a statistical approach to a consideration of the French nautical sector which was organized around the following eight activities (the construction and import of boats, nautical equipment...). Boating sector firms were identified using the 30 codes designated by the Nomenclature of Economic Activities in the European Community Revision 2 (NACE Rev. $2^{1}$ ).

Our research questionnaire was constructed in eight parts to collect primary data: a profile of the respondent and his firm, the reasons for collaboration, the management and governance of the project, the nature of the partners and their exchanges, and the market shares of the firms during the project. To maximize its effectiveness, the questionnaire was

\footnotetext{
${ }^{1}$ The NACE code list is available from the authors on request.
} 
carried out in three stages: we wrote a first version related to our research objectives, pretested this with a small number of representative individuals, and incorporated the resulting changes into the final draft together with a pre-coding system to facilitate computer input of the answers. The questionnaire was sent to 2,290 French firms in the boating industry. These firms were selected after applying a simple random sampling method, thus ensuring the representativeness of our sample by giving each unit in the population an equal chance of being selected. The random sampling (method) allowed us to mobilize the rules of statistical inference: the properties and the intentions of the target population were selected from our survey sample. In accordance with our objective of describing and explaining co-opetition, statistical inferences require a minimum of 30 respondents for a descriptive analysis, and a minimum of 100 respondents for an explanatory analysis. After receiving 115 contributions to our survey, 106 ETIs and SMEs were selected due to the satisfactory level of information included in their questionnaire. Of the respondents, $85 \%$ held a position of responsibility (69.60\% were CEOs, COOs or managing partners; $15.4 \%$ were service managers). Finally, secondary data complemented the primary data from the questionnaire to identify some of the structural variables of the firms (e.g. effective, size and age). These secondary data were obtained from three databases: Diane, the Nautical Industries Federation database, and the Figaro sailboat database. Our statistical analysis was performed using SPSS and AMOS software.

\section{Data processing}

Once the factorial scores (principal component analysis [PCA] and common factor analysis $[\mathrm{CFA}]$ ) were obtained from the rotations providing the maximum amount of information, a typological analysis allowed us to identify five groups of companies. This classification, which was validated by discriminant analysis, was categorized by studying the 
following groups of variables: "Relational modes" and "Environment and networks" (excluding vertical and institutional networks). By virtue of the scores and centroids, we could identify whether a variable varied more or less for a certain group. We could then compare the groups on this basis. ANOVA determined whether an independent variable had a significant influence on a dependent variable. Multiple comparison tests, referred to as MCTs in the text (t-tests, Tukey with unequal group sizes, Scheffé, least significant difference and Bonferroni), were carried out to identify the implications of the groups of companies. Determining the variables that are explicative of a "Horizontal collaborative network" was carried out using stepwise multiple regression models.

\section{RESULTS}

\section{Variables}

All scales have been validated after the purification process: PCA/CFA (see Table 1.).

\section{Insert Table 1.}

\section{Dependent variable}

Complex horizontal network: A business network is a collection of competitive and collaborative relationships (Gnyawali and Madhavan, 2001). In this sense, Dagnino and Padula (2007) talk of a complex co-opetition network involving several firms that decide to co-operate, while simultaneously competing. Thus, the complex horizontal network variable is related to the diversity of the collaborations between rivals. This variable relates to the multiplicity of rivals engaged in a collective project (Lambe et al., 2002) and measures the extent of the connections between competitors. It allows us to distinguish between a simple co-opetitive network (dyadic) and a complex co-opetitive network (among more than two 
multiple competitors). The items of the scale were suggested by an article by Bengtsson et al. (2010).

\section{Independent variables}

Twelve groups of variables were identified.

Relational modes: Four variables measure the relationships that firms maintain with each other (competition, alternating between competition and co-operation, defence, and the simultaneity of competition and collaboration). The scale items were inspired by those of Powell et al. (1996) and Gulati et al. (2000).

Environment and network: The economic and relational extent of a firm is measured through

four sectoral and geographic dimensions (single-sector environment, single-point environment, multi-sector environment, and multi-point environment) and two vertical collaboration dimensions (institutional network and vertical network). The scale items were suggested by Lambe et al. (2002).

Asymmetries: Asymmetry between competitors is defined through the dissimilarity of their resources, their learning or their position and influence in their shared environment. First, the asymmetries between partners are measured in their influences, positions, sizes, market shares, connections and collaborative experiences. Their decisions during the joint project, their knowledge and their managerial and technological resources are then measured. The scale items were inspired by Young-Ybarra and Wiersema (1999).

Resources: Firstly, this group of variables measures the contributions of partners to a collaboration based on their commercial, technological, organizational and human resources. Secondly, the creation of technological, financial and organizational resources is measured. Thirdly, the characteristics of their resources, estimated as unique by their partners, are 
evaluated. The scale items were inspired by Young-Ybarra and Wiersema (1999) and Kale and Singh (2009).

Activities: Resources are related to the internal capabilities of a firm to create value through the activities of its value chain. After the PCA and CFA, only the production and distribution activities are selected. The scale items were mainly inspired by Wiklund and Shepherd (2009).

Learning: This group of variables measures the ability to create and exploit organizational knowledge. Information learning measures the characteristics of the firm's information management. Knowledge learning measures the development of knowledge related to the human, physical, technological, organizational and business abilities of partners.

Trust: The essential place of trust in co-opetitive relationships (Bengtsson et al., 2010) encouraged us to attempt to measure it through the following factors as they apply to the relationship between partners: perception, equity, integration, reliability, honesty, ethics, reputation and sincerity. The scale items were inspired by Parkhe (1993) and Young-Ybarra and Wiersema (1999).

Risks: Co-opetition is a risky strategy because of the unpredictable and opportunistic behaviour of partners, so the risk of default, opportunistic risk and resources risk are measured and, finally, we wanted to measure the reaction to opportunistic risk. The scale items were suggested by Parker (2012).

Initiative and aims: Collaboration with rivals may be suggested or imposed on a firm but is still measured through the collaborative initiative. This group of variables also measures individual and collective market defence, the strengthening of market presence, and the pursuit of personal projects and technological developments. The scale items were inspired by Todeva and Knoke (2005). 
Choice of allies: A firm chooses its partners according to several criteria (Gnyawali and Park, 2009): market position, competence and collaborative experience. The scale items were created ex nihilo.

Organization: This group of variables measures contracting with respect to collaborative relationships, joint projects and consortia, and control over collaboration and compliance, of a consortium, the control over the collaboration and compliance. The composition of a joint project is critical to the commitment of firms and their collective success. Thus, we measure the involvement of external and internal actors. The scale items were inspired by Parkhe (1993) and Todeva and Knoke (2005).

Opportunism: The vulnerability a firm faces from the opportunistic behaviour of other firms. The threat of economic and social sanctions discourages opportunism. Thus, we measure single-point single-sector sanctions at the launch of the project, the multi-sector sanctions during its decline, and the multi-point multi-sector sanctions during its launch, during its growth and upon its maturity. The scale items were inspired by Uzzi (1997).

\section{Control variables}

Four control variables were mobilized for the study: the size of the firm (its effective size), its turnover, the date it was established and its membership of a group. The first three variables are filled by secondary data collected through various digital databases (e.g. Kompass and Diane). The final variable was suggested by Belderbos et al. (2004).

\section{Five groups of firms identified}

Which firms adopt a co-opetitive behavior? Scores relating to the barycentres are shown in brackets $(\mathrm{G})$. 
The Multi-point and multi-market competitors (Group 1) diversify $(\mathrm{G}=0.906)$ and internationalize their activities $(G=0.735)$ through defensive relationships $(G=0.065)$ with their competitors that are competitive $(G=0.058)$ and complex $(G=0.284)$.

The Mono-point and mono-market partners (Group 2) conduct a single activity ( $\mathrm{G}=$ $1.023)$ in a single domestic market $(\mathrm{G}=0.400)$ through collaborative relationships $(\mathrm{G}=$ $0.359)$ with their competitors that are defensive $(G=0.163)$ and dyadic $(G=-0.103)$.

The Mono-point and mono-market co-opetitors (Group 3) develop a single activity (G $=0.348)$ in a single domestic market $(G=1.142)$ via co-opetitive $(G=0.137)$ and dyadic $(G=$ -0.248) relationships with their competitors.

The Multi-market co-opetitors (Group 4) diversify (G>1) without a dominant geographic strategy $(G<1)$ via co-opetitive $(G=0.626)$ and dyadic $(G=-0.464)$ relationships with their competitors.

The Multi-point co-opetitors (Group 5) internationalize (G>0) without a dominant sector strategy $(G<0)$ through competitive $(G=0.663)$, defensive $(G=0.656)$, collaborative $(\mathrm{G}=0.438)$, co-opetitive $(\mathrm{G}=0.204)$, and complex dyadic $(\mathrm{G}=0.295)$ relationships with their competitors.

\section{Four discriminant functions identified}

Which variables distinguish the more competitors, allies and co-opetitors?

The discriminant power of our classification is $93.84 \%$. According to the Fisher's and Wilks's lambda tests, the Mono-environment and Multi-environment variables differentiate more firms.

Four discriminant functions are identified (discriminating power of 97.90\%). 
Co-opetition committed (function 1) has positive scores for Relational modes and a Complex horizontal network. This co-opetition strengthens and pools the collective actions of many Multi-point co-opetitors (centroid = 3.019).

Independent co-opetition (function 2) has negative scores for Relational modes and for Complex horizontal network. This suggests a high degree of independence in co-opetition for Mono-point and mono-market co-opetitors (centroid $=2.373$ ), which minimizes and sometimes prevents their interactions with other firms.

A Pooled alliance (function 3) has positive scores for Relational modes (except for coopetition) and Complex horizontal network. This type of project is characterized by alternating co-operative and competitive relations between Mono-point and mono-market partners $($ centroid $=1.252)$ which are part of a strong common collaborative network.

Opportunistic co-opetition (function 4) has positive scores for Relational modes and negative scores for Complex horizontal network. This type of co-opetition defines competitive relations and concurrent collaboration between Multi-market co-opetitors $($ centroid $=0.606$ ) that adopt individualistic attitudes despite their collective commitment.

\section{Complex horizontal network characteristics by group}

Scores relating to barycentres (G) and significance levels for the Fisher's test (p) are shown in brackets below.

We note a significant difference $(p<0.05)$ between the five groups in relation to the sharing of a complex horizontal network. The variable strongly characterizes the Multi-market co-opetitors $(\mathrm{G}=2.460)$, Single-point and single-market co-opetitors $(1.451)$ and Multi-point co-opetitors (0.544) groups, which have a positive barycentre. However, the groups of Single- 
point and single-market allies (-1.134) and Multi-point and multi-market competitors (-0.376) have negative barycentres. As part of the MCT, the Multi-market co-opetitors differ from the Multi-point and multi-market competitors and Multi-point co-opetitors regarding the degree to which they share an extended and complex horizontal network $(\mathrm{p}<0.05)$. The more a relationship is co-opetitive, the more the complex horizontal network is shared.

Multi-market co-opetitors differ from Multi-point co-opetitors $(\mathrm{p}<0.05)$ and Multipoint and multi-market competitors $(\mathrm{p}<0.05)$ regarding the degree to which they collaborate with several allies: the more a firm engages in multi-market co-opetition, the more the firm collaborates with several allies. Moreover, Multi-point co-opetitors are also distinguished from Multi-market co-opetitors $(\mathrm{p}<0.05)$ regarding the degree to which they share a complex horizontal network: the more a firm engages in multi-point co-opetition, the more the firm collaborates with several competitors.

Finally, Multi-market co-opetitors differ from Multi-point co-opetitors $(\mathrm{p}<0.05)$ and Multi-point and multi-market competitors $(\mathrm{p}<0.05)$ regarding the degree to which they collaborate with several competitors during a project: the more a firm engages in multimarket co-opetition, the more the firm collaborates with several competitors. Moreover, Multi-point co-opetitors are also distinguished from Single-point and single-market allies $(\mathrm{p}<$ $0.01)$ and Multi-market co-opetitors $(\mathrm{p}<0.05)$ regarding the degree to which they share a complex horizontal network: the more a firm engages in multi-point co-opetition, the more the firm collaborates with several competitors.

Thus, a diversified and/or internationalized firm develops a strategy of co-opetition based on a horizontal network of multiple partners. The horizontal network is complex when the sectoral and territorial extent of co-opetition is important. Hypotheses $\mathrm{H} 2$ and $\mathrm{H} 4$ are validated and hypotheses $\mathrm{H} 1$ and $\mathrm{H} 3$ are rejected. 


\section{Determinants of an extended and complex horizontal network}

We saw what distinguishes groups according to their level of collaboration. Now, we will see what explains the membership of a complex horizontal network for each group. The stepwise regression model considered the complex horizontal network as the dependent variable. Thus, depending on the level of collaboration, is the dependent variable, the membership of a complex horizontal network, different from one business group to another? For reasons of simplicity, we only present the results that were statistically significant (see Table 2.).

Insert Table 2.

The group of Multi-point and multi-market competitors now shares a more complex horizontal network and there is asymmetry in decisions related to technological resources.

For the group of Single-point and single-market allies no result. However, the more a company shares an extended/horizontal network and less complex company creates organizational resources is offensive, the less power asymmetry between the allies.

The group of Single-point and single-market co-opetitors now shares a more complex horizontal network and the company manages information related to the project.

The group of Multi-market co-opetitors now shares a more complex horizontal network and contracts exist for the project.

The group of Multi-point co-opetitors now shares a more complex horizontal network and the company pools its production activities. However, the more a company shares an extended/horizontal network and less complex the alliance is imposed on the company, unless the company manages information related to the project, creates organizational resources. 


\section{DISCUSSION}

According to Bengtsson and Kock (2014), a better understanding of co-opetition now requires further analysis of the relationships between the multiple firms involved, in order to extend such study beyond that of simple dyadic relationships. However, does the complexity of collaborative relationships between rivals characterize co-opetitive strategies? To answer this question, our study identified three major findings.

Our first result shows the existence of five groups of firms according to their level of cooperation and their degree of involvement within firm networks.

Competitors have diversified and internationalized market-building relationships with a multitude of rivals with the same profile. A multi-point and multi-market rivalry is a competitive form that emerges when firms engage each other in several industries (products/services) and/or in several distinct geographical markets (Baum and Korn, 1999). Joint participation in various markets creates a network of links between rivals that reduces their will for conflict and facilitates coordination (Bernheim and Whinston, 1990).

Allies have specialized locally through a relational alternation between competition and co-operation that has allowed them to forge co-operative relationships with fewer rivals. An alliance is presented via a succession of competitive and collaborative relationships as part of a dyadic relationship between two rival firms (Bresser, 1988). Firms therefore realize alliances with a few opponents to specialize and diversify.

Three forms of co-opetitors are identified. Co-opetition is multifaceted (Gnyawali and Park, 2009). First, co-opetitors, following a local specialization strategy, rely on co-opetitive relationships involving fewer rivals (a simple network). Second, co-opetitors engaging in a diversification strategy are also doing so based on co-opetitive relationships with a small number of rivals. Finally, co-opetitors leading an internationalization strategy rely on coopetitive relationships developed with a significant number of competitors (a complex 
network). The literature shows that co-opetition does not evolve only within a single network (a dyadic relationship), but also within a complex network of multiple actors (Gnyawali and Madhavan, 2001). Luo (2007) states that a strategy of co-opetition can take place in some domestic or international markets. Bengtsson et al. (2010) state that a firm can remain in its business core or develop new activities through a strategy of co-opetition. In this sense, our study confirms that a strategy of co-opetition can bring together two or multiple competitors depending on their sectoral and territorial policy. A collaborative relationship between rivals remains straightforward when they favour a sectoral approach (markets). This collaborative relationship becomes complicated when they engage in an internationalization approach (territories).

These results clearly show the atomicity of boating markets. Local actors operate in several markets and, consequently, the number of different actors in a given market is reduced. Boating firms encounter the same actors from one market to another because most of them are positioned in a small geographical area. This geographical concentration then accentuates the simple relationships between actors positioned in several markets. Indeed, a firm can work with only one competitor and still gain a foothold in several markets at once. On the one hand, a firm reduces its costs by limiting collaboration to one partner. On the other, the firm commits its resources and competences with this same partner to take advantage of its position in several markets. When the firm expands its presence to other geographical areas, it faces a number of important competitors. The relations that a firm has with local partners are not sufficient to conquer markets in other world areas. The firm must acquire new competences and resources to access markets in these new geographical areas. Therefore, a strategy of co-opetition takes the form of a real complex collaborative network of competitors that allows a firm, which initially operated locally, to learn and to position itself in hitherto unknown geographical areas. 
Luo (2007) notes that the importance of co-operation between rivals in the process of internationalization can come from their ability to provide information, knowledge and resources to pursue their goals as they evolve in the same sector of activity. Kock et al. (2010) argue that a strategy of co-opetition reduces the costs of a policy of territorial expansion of a firm, in order to develop a transnational network faster, better share information and knowledge, increase the speed of its operations in distant markets and to facilitate a global distribution of what it is offering. Thus, a complex network allows co-opetitors to mobilize a high volume and diversity of resources and competences to conduct global operations effectively. Each competitor mobilizes its personal connections to provide a strong coopetitive effort.

From this it can be seen that simple co-opetitive relationships are characterized by a sectoral dimension while, however, complex co-opetitive relationships are characterized by a geographical dimension. Thus, there are two forms of co-opetition: local co-opetition, where simple relationships are established between competitors, and global co-opetition, where complex relationships are established between competitors.

Our second result identifies three discriminant functions where co-opetition can be committed independent and opportunistic. The first is characterized by a strong expansion of the geographical area of a firm, while the other two concern a wide diversification of its markets.

Diversification reflects simple collaborative relationships between rivals that are more oriented towards opportunism and the independent actions of the partners. A diversification strategy requires a firm to possess numerous and diverse resources to make and distribute an extensive portfolio of offers. Collaboration can support this policy through access to resources and complementary competences that are otherwise unavailable, as co-opetition encourages the expansion of portfolios of products or services. But as it is unwound, firms might have to 
compete for the collective work, which increases their competitive capabilities (Lado et al., 1997). Moreover, the opportunity for competitors to access external resources and to make up for the downsides with regard to their rivalry stimulates specific competencies (Hamel et al., 1989). Thus, co-operation can be sought in order to improve the individual competitiveness of a firm in a new competitive arena. A significant multi-market convergence promotes strong rivalry during the co-opetitive phase (Luo, 2007), which can generate opportunism (M'Chirgui, 2005). Therefore, the environmental complexity of diversified co-opetition is mostly controlled by maintaining a simple relationship. The establishment of a privileged and exclusive relationship between two firms encourages co-opetitive relationships that remain fragile and whose negative outcomes can have a negative multi-market impact. Thus, firms mitigate this relational risk by the mobilization of a single collaborative network.

The internationalization of actors favours more complex collaborative relationships that are based more on exchange, sharing and pooling. The actors in a global co-opetition have two main objectives. First, co-opetition allows them to access new foreign markets through the strategic mobilization of the resources required for such an approach (Hamel et al., 1989). One firm alone is unlikely to have sufficiently large and heterogeneous resources, the ability to adapt strategic capacity and the transcultural competence to ensure its global competitiveness. Second, global co-opetition also meets the need of the firm to reduce costs and improve the efficiency of some of the activities in the value chain (Luo, 2007). The collaborative network, therefore, remains complex in order to group all of the components needed for flexibility and the organizational efficiency of the firm based in several geographical markets. It is through the sharing of their respective resources than many competitors can support their geographical expansion. Their individual success depends on co-opetition with a dominant collaborative behaviour that enables the development of a strong interdependence between partners and a high degree of mutual commitment. In contrast, the 
search for resources and competences is seen as less central in the diversification policy of the firm because it is operating in its historical territory. Thus, the sectoral dimension emphasizes the simplification of co-opetitive relationships, strengthens the opportunistic nature of a firm and encourages the firm to be more independent vis-à-vis its partners. Co-opetition is a deliberately framed action in a simple relational structure that is undertaken in order not to jeopardize the status and competitive position of the firm vis-à-vis its rivals. The preponderance of the geographical dimension in the strategic policy of the firm precludes opportunistic behaviour because of a lack of knowledge of the foreign markets that the firm wants to conquer. This dimension directs the firm to a behaviour of exchanging, sharing and pooling its achievements with its partners in order to learn about the new geographical environment. The firm's expertise and learning, related to the management of an international structure, are powered by its co-opetitive relationships. Gradually, the firm develops a specific capacity in the management of a number of technically, geographically and culturally distant tasks. Co-opetition thus transforms a national firm into a multinational one through the requirement to take advantage of collaborative behaviour. In this sense, the distinction between the sectoral and the geographical dimensions is supported by the MCT conducted in our study.

Our third result shows the determinants of complex horizontal relationships between firms. These were identified in the stepwise multiple regression models.

An openness to new territories is presented as an important factor in the complexity of collaborative relationships that can be built and maintained by a firm with several of its rivals. The mobilization of a complex network provides a significant pooling of resources and competences competences to enable the geographical expansion of rivals. These rivals are also compelled to coordinate the activities of their respective value chains. Co-opetition can extend over one or more activities (Padula and Dagnino, 2007). According to Luo (2007), all 
the primary and support activities of a value chain are affected by global co-opetition. The actions of co-opetitors may involve the gathering of their complementary competences, control over production costs, the speed and efficiency of the distribution of offers, and so on. A complex network facilitates the strategic expansion of a firm into the territories of its many rivals. The overlap of their territories promotes collaboration in order to maintain their spheres of influence and enable them to compete with rivals. In addition to supporting their implementation, the complex network mobilized during co-opetition reduces the intensity of competition in the global environment of the firm.

Market diversification is one of the determinants of a simplification of collaborative relationships between rivals. These dyadic relationships are characterized by the optimal management of information related to the implementation of a joint project by a stronger contractualization of collaboration and a reduction of the pooling of resources and competences. The building of a simple network serves the desire of the firm to manage and control its co-opetitive relationship with trusted rivals. As part of global co-opetition, the project is based on the establishment and animation of complex relationships. These allow the firm to share and exchange large and heterogeneous resources and competences with multiple partners to ensure the success of its global expansion.

Thus, the sector or geographic strategy of a firm guides its choice during co-opetition between the security of a single collaborative network or the risk-taking of a complex collaborative network.

\section{CONCLUSION}

Our study refines the definition of the term 'co-opetition' and demonstrates that the phenomenon is multi-faceted (Gnyawali and Park, 2009). Co-opetition has been defined as 
the simultaneity of competitive and co-operative relationships between a number of rivals who act in a complex network (Padula and Dagnino, 2007). However, research on coopetition in business networks is still rare (Bengtsson and Kock, 2014) and, therefore, it is necessary to conduct more research in this area in order to improve our knowledge of the phenomenon.

Theoretical implications show that our results support this definition only when the objectives of a firm are part of the geographical expansion of its activities. In contrast, these relations remain simple (dyadic) when a firm favours a strategy of diversifying its activities while maintaining its unique local geographical market. The sectoral and geographical nature of the firm's strategy also focuses its behaviour during the strategy of co-opetition. Our study reveals that the individualistic behaviour of co-opetitors is generally associated with the geographical expansion of the firms' market. In contrast, a sectoral policy based on diversification causes a high level of commitment from co-opetitors in the collective effort required by a joint project. A marketing or internationalization strategy has the effect of increasing the density of the network of firms on the one hand, and developing co-opetitive behaviour on the other. Thus, co-opetition strategies result in a more complex network because firms are diversifying and becoming international. The number of potential partners is particularly important if a firm's geographic and sectoral activity area is being extended. The firm can offer greater/closer partnerships with its direct competitors (including foreign firms) and indirect competitors (including other markets). By establishing multiple relationships with rivals, the firm develops its knowledge in its new target markets (discovery of new customer opportunities, etc.) and its new host regions (local adaptation, etc.). Coopetition in a complex network then allows the firm to gain time to understand geographic and sectoral threats/opportunities by relying on a business network that is already in place geographically and sectorally. 
The methodological implications of our quantitative study allow generalization from the results. Our descriptive and explanatory statistical analysis was used to quantify a phenomenon that remains largely understood through qualitative methods conducted by previous researchers. For example, the validity of our measurement scales from CFA allows it to be reused in future research, so it can be demonstrated that our study forms a link between exploratory studies in previous research and a confirmation of the relations between the different variables.

In our view, the managerial implications of this research are manifold. Our results provide decision makers with levers to implement a strategy of co-opetition. The operationalization of this study is the identification of key indicators to be put in place to ensure an adequate level of network management of firms based on the geographic and sectoral scopes desired by a decision maker. The latter can define the shape of a co-opetitive strategy according to the sectoral scope specified. The complexity makes it more difficult to manage a co-opetitive strategy. Thus, knowledge of areas of work on which decision makers should focus will help balance the difficult equation between increasing network complexity and will co-opetitive relationships.

Any study accepts some limitations. First, our research is based on a quantitative methodology (a static approach). It would be interesting to study the process of the establishment of collaborative relationships between rivals, notably through a qualitative study. Second, our study concerns French boating firms. It would be interesting to study/observe the experience of non-French firms with regard to the notion of so-called simple or complex relationships. Third, it may be useful (and perhaps more relevant) to distinguish a simple relationship from a dyadic one, and a globalization strategy from an international one. 


\section{REFERENCES}

Assens C. (2003), "Le réseau d'entreprises: vers une synthèse des connaissances", Management International, Vol.7, No.4, pp. 49-59.

Baum J. A. and Korn H. J. (1999), "Dynamics of dyadic competitive interaction", Strategic Management Journal, Vol.20, No.3, pp. 251-278.

Belderbos R., Carree M., Diederen B., Lokshin B. and Veugelers R. (2004), "Heterogeneity in R\&D cooperation strategies", International Journal of Industrial Organization, Vol.22, No 8, p. 1237-1263.

Bengtsson M. and Kock S. (2000), "Co-opetition in business networks-to cooperate and compete simultaneously", Industrial Marketing Management, Vol.29, No 5, pp.411-426.

Bengtsson M. and Kock S. (2014), "Co-opetition - Quo vadis? Past accomplishments and future challenges", Industrial Marketing Management, Vol.43, p:180-188.

Bengtsson M., Wilson T., Eriksson J. and Wincent J. (2010), "Co-opetition dynamics - an outline for further inquiry", Competitiveness Review: an International Business Journal, Vol.20, No 2, pp. 194-214.

Bernheim B. D. and Whinston M. D. (1990), "Multimarket contact and collusive behavior", The RAND Journal of Economics, Vol.21, No 1, pp. 1-26.

Bouncken R.B., Gast J., Kraus S. and Bogers M. (2015), "Co-opetition: a systematic review, synthesis, and future research directions", Review of Managerial Science, Vol.9, No3 , pp 577-601.

Bresser R. K. (1988), "Matching collective and competitive strategies", Strategic Management Journal, Vol.9, No 4, pp. 375-385.

Burt R. S. (2012), Structural Holes, Contemporary Sociological Theory.

Coy P. (2006), "Sleeping with the enemy", Business Week, pp. 96-97. 
Dagnino G. B. and Padula G. (2007), "La dynamique des stratégies de coopétition", Revue française de gestion, Vol.7, pp.87-98.

Dyer J. H. and Singh H. (1998), "The relational view: co-operative strategy and sources of interorganizational competitive advantage", Academy of Management Review, Vol.23, No 4, pp. 660-679.

Enberg C. (2012), "Enabling knowledge integration in co-opetitive R\&D projects: the management of conflicting logics", International Journal of Project Management, Vol.30, No7, pp:771-780

Gast J., Filser M., Gundolf K. and Kraus S. (2014), "Co-opetition research: Towards a better understanding of past trends and future directions", International Journal of Entrepreneurship and Small Business, Vol. 24, No4, pp:492-521.

Gnyawali D. R. and Madhavan R. (2001), "Co-operative networks and competitive dynamics: A structural embeddedness perspective", Academy of Management review, Vol.26, n³, pp:431-445.

Gnyawali D. R. and Park B.-J. R. (2009), "Co-opetition and technological innovation in small and medium-sized enterprises: a multilevel conceptual model", Journal of Small Business Management, Vol.47, No 3, pp. 308-330.

Gomes-Casseres B. (2003), "Competitive advantage in alliance constellations", Strategic Organization, Vol.1, No 3, pp. 327-335.

Gulati R. (1998), "Alliances and networks", Strategic Management Journal, Vol.19, No 4, pp. 293-317.

Gulati R. and Gargiulo M. (1999), "Where do interorganizational networks come from?", American Journal of Sociology, Vol.104, No 5, pp. 1439-1493.

Gulati R., Nohria N. and Zaheer A. (2000), "Strategic networks", Strategic Management Journal, Vol.21, No 3, pp. 203-215. 
Hamel G., Doz Y. L. and Prahalad C. K. (1989), "Collaborate with your competitors and win", Harvard Business Review, Vol.67, No 1, pp. 133-139.

Jarillo J. C. (1988), "On strategic networks", Strategic Management Journal, Vol.9, No 1, pp. 31-41.

Jones, C., Hesterly, W., Borgatti, S. (1997). "A general theory of network governance: Exchange conditions and social mechanisms", Academy of Management Review, Vol. 22, No 4, p. 911-946.

Kale P. and Singh H. (2009), "Managing strategic alliances: What do we know now, and where do we go from here", Academy of management perspectives, Vol.23, no 3, p.45-62.

Kock S., Nisuls J. and Soderqvist A. (2010), "Co-opetition: a source of international opportunities in Finnish SMEs", Competitiveness Review: An International Business Journal Incorporating Journal of Global Competitiveness, Vol.20, No 2, pp. 111-125.

Lado A. A., Boyd N. G. and Hanlon S. C. (1997), "Competition, co-operation, and the search for economic rents: a syncretic model", Academy of Management Review, Vol.22, No 1, pp. 110-141.

Lambe C. J., Spekman R. E. and Hunt S. D. (2002), "Alliance competence, resources, and alliance success: conceptualization, measurement, and initial test", Journal of the academy of Marketing Science, Vol.30, No 2, p.141-158.

Larson A. (1992), "Network dyads in entrepreneurial settings: a study of the governance of exchange relationship"s. Administrative Science Quarterly, Vol.37, No 1, pp. 76-104.

Lazega E. (1992), "Analyse de réseaux d'une organisation collégiale: les avocats d'affaires", Revue française de sociologie, Vol.33, No 4, pp. 559-589.

Levin M. A. and McDonald R. E.( 2006), "R-A theory as a post-Chicago argument for legal co-opetition", The Marketing Management Journal, Vol.6, No 2, pp. 1-12. 
Luo X., Slotegraaf R. and Pan X. (2006), "Cross-functional "co-opetition": the simultaneous role of co-operation and competition within firms", Journal of Marketing, Vol.70, No 2, pp:67-80.

Luo Y. (2007), "A co-opetition perspective of global competition", Journal of World Business, Vol.42, No 2, pp. 129-144.

M'Chirgui Z. (2005), "The economics of the smart card industry: towards co-opetitive strategies", Economics of Innovation and New Technology, Vol.14, No 6, pp. 455-477.

Miles R. E. and Snow C. C. (1986), "Network organizations: new concepts for new forms", California Management Review, Vol.28, pp.62-73.

Nooteboom B., Berger H. and Noorderhaven N. G. (1997), "Effects of trust and governance on relational risk", Academy of management journal, Vol.40, No 2, pp. 308-338.

Padula G. and Dagnino G. B. (2007), "Untangling the rise of co-opetition: the intrusion of competition in a co-operative game structure", International Studies of Management and Organization, Vol.37, No 2, pp. 32-52.

Parkhe A. (1993), "Strategic alliance structuring: A game theoretic and transaction cost examination of interfirm cooperation", Academy of management journal, Vol.36, No 4, p.794-829.

Parker H. (2012), "Knowledge acquisition and leakage in inter-firm relationships involving new technology-based firms", Management Decision, Vol.50, No 9, p. 1618-1633.

Powell W. W., Koput K. W. and Smith-Doerr L. (1996), "Interorganizational collaboration and the locus of innovation: Networks of learning in biotechnology", Administrative science quarterly, Vol.41, p.116-145.

Prashant K. and Singh H. (2009), "Managing strategic alliances: what do we know now, and where do we go from here?", The Academy of Management Perspectives, Vol.23, No 3, pp. 45-62. 
Ritala P. (2012), Co-opetition strategy-when is it successful? Empirical evidence on innovation and market performance, British Journal of Management, Vol.23, No 3, pp:307324.

Salvetat D. and Géraudel M. (2011), "Comprendre le rôle de l’intermédiation dans la coopétition: le cas des industries aéronautiques et spatiales", Management international/International Management/Gestiòn Internacional, Vol.15, No 2, pp:67-79.

Swaminathan V. and Moorman C. (2009), "Marketing alliances, firm networks, and firm value creation", Journal of Marketing, Vol.73, No 5, pp. 52-69.

Tomaszewski M. (2013), “Chosen determinants of co-opetition between the industrial companies of the Lubusz region in the 2009-2011 period", Management, Vol.17, No 1, p.219232.

Thorelli H. B. (1986), "Networks: between markets and hierarchies", Strategic management journal, Vol.7, No 1, pp:37-51.

Todeva E. and Knoke D. (2005), "Strategic alliances and models of collaboration", Management Decision, Vol.43, No 1, p. 123-148.

Tsai W. (2002), "Social structure of "co-opetition" within a multiunit organization: Coordination, competition, and intraorganizational knowledge sharing", Organization science, Vol.13, No 2, pp:179-190.

Uzzi B. (1997), "Social structure and competition in interfirm networks: The paradox of embeddedness", Administrative science quarterly, Vol.42, No 1, p.35-67.

Wang C., Rodan S., Fruin M. and Xu X. (2014), "Knowledge Networks, Collaboration Networks, and Exploratory Innovation? ", The Academy of Management Journal, Vol.57 No2, p:484-514. 
Wang Y., Hutchinson J., Okumus F. and Naipaul S. (2013), "Collaborative Marketing in a Regional Destination: Evidence from Central Florida", International journal of tourism research int. J. Tourism Res., Vol.15, p: 285-297.

Wiklund J. and Shepherd D. A. (2009), "The effectiveness of alliances and acquisitions: The role of resource combination activities", Entrepreneurship Theory and Practice, Vol.33, No 1, p.193-212.

Wilhelm M. and Kohlbacher F. (2011), "Co-opetition and knowledge co-creation in Japanese supplier-networks: The case of Toyota", Asian Business \& Management, Vol.10, No1, p. 66-86.

Young-Ybarra C. and Wiersema M. (1999), "Strategic flexibility in information technology alliances: The influence of transaction cost economics and social exchange theory", Organization science, Vol.10, No 4, p. 439-459. 
